bilirubin from the surface of the liver it is important that the ascites is not returned to the circuit during clinical perfusions. Benefit to the patient from the synthetic functions of the pig liver is likely to be small because of the limited time that perfusion is possible with human blood. Longer time is available with primate livers (either baboon or cadaver human), and Abouna et al. (1970) showed the potential of primate livers and indeed of the whole concept of extracorporeal perfusion in their report of survival of a patient with complete hepatic failure for two-and-a-half months using a total of 16 perfusions.

The lack of long-term survival in our patients is not surprising for all were treated at a very late stage of their diseace. It may well be that as with remal dialysis treatment will be more successful if carried out before serious metabolic complications have occurred. To do this, however, we must be sure that the liver placed in the extracorporeal circuit is safe haematologically as well as having adequate biochemical function. It is in this context that the ${ }^{125} \mathrm{I}$ fibrinogen test may prove to be of considerable help.

We wish to thank Dr. P. T. Flute and Dr. M. O. Rake for their help and advice, and Dr. R. A. Zeitlin and Dr. J. V. Barry, of the South London Transfusion Centre, for the supply of fresh human blood. This work was supported by a generous grant from the Wates Foundation.

\section{References}

Abouna, G. M. (1968). British fournal of Surgery, 55, 761.

Abouna, G. M., Kirkley, J. R., Hull, C. J., Ashcroft, T., and Kerr, D. N. S.

(1969). Lancet, 1, 64. G. (1970). Lancet, 2, 391 .

Abouna, G. M., Fisher, L. McA., Still, W. J., and Hume, D. M. (1972). British Medical fournal, 1, 23.

Battersby, C., Winch, J., Balderson, G., Cranitch, B., and Burnett, W. (1971). Australian and New Zealand fournal of Surgery, 40, 302.

Condon, R. E., and Bombeck, C. T. (1970). Surgical Clinics of North America, 50, 257.

Eiseman, B. (1966). Annals of the Royal College of Surgeons of England, 38,

Eiseman, B., Knipe, R., McColl, R. A., and Orlof, M. J. (1961). Archives of Surgery, 83, 356

Hutchinson, D. E., et al. (1968). Archives of Surgery, 93, 27.

Norman, J. C., Savaris, C. A., Brown, M. E., and McDermott, W. V., jun. (1966). Surgery, 60, 179 .

Parbhoo, S. P., et al. (1971). Lancet, 1, 659.

Rake, M. O., Flute, P. T., Pannell, G., and Williams, R. (1970). Lancet, 1,

Rake, M. O., et al. (1971). Lancet, 2, 1215.

Ranek, L., et al. (1971). Scandinavian Journal of Gastroenterology, Suppl. No. 9 , p. 161.

Sen, P. K., et al. (1966). Surgery, 59, 774.

Strebei, H. H., et al. (1969). Langenbecks Archiv für kliniche Chirugie, 325, 1118.

Trey, C., and Davidson, C. S. (1970). In Progress in Liver Disease, ed. H. Popper and F. Schaffner, vol. 3, chap. 18, p. 282. London, Heinemann. Watts, J. McK., Douglas, M. C., Dudley, H. A. F., Gurr, F. W., and Owen, J. A. (1967). British Medical fournal, 2, 341.

Winch, J. (1971). British Medical fournal, 1, 216.

\title{
Effect of Vagotomy on Ascorbic Acid Nutrition in Patients. with Peptic Ulcer
}

\author{
J. A. E. MACDONALD, M. M. COHEN
}

British Medical fournal, 1972, 2, 738-740

\section{Summary}

In 33 patients undergoing surgery for peptic ulcer it was found that both the dietary and the leucocyte ascorbic acid levels fell below the accepted normal values. Although after vagotomy the dietary intake improved dramatically, this was accompanied by only a small rise in leucocyte ascorbic acid levels. Evidence has been presented that the reduction in gastric acid output after vagotomy might be responsible for this paradox.

\section{Introduction}

Patients suffering from peptic ulcer have consistently low blood ascorbic acid levels (Archer and Graham, 1936; Harris, Abbasy, Yudkin, and Kelly, 1936; Platt, 1936; Lazarus, 1937; Portnoy and Wilkinson, 1938). The leucocyte ascorbic acid is generally regarded as the most reliable index of ascorbic acid nutrition (Bartley, Krebs, and O'Brien, 1953), and this too has been shown to be lowered in patients suffering from gastroduodenal disorders, including peptic ulcer (Cohen, 1967). These patients may have a reduced dietary intake of ascorbic acid, and this probably explains their poor nutritional status (Cohen and Duncan, 1967). With the restoration of a normal diet after successful surgery for duodenal ulcer, one might expect a

Department of Surgery, Western Infirmary, Glasgow W1

J. A. E. MACDONALD, M.B., CH.B., F.R.C.S., Surgical Registrar

M. M. COHEN, M.B., CH.B., F.R.C.s., Surgical Registrar (Present address Department of Surgery, Vancouver General Hospital, Vancouver 9, Canada)

similar improvement in leucocyte ascorbic acid levels. A study of a small group of patients, however, has shown that while there may be an appreciable improvement in ascorbic acid nutrition after vagotomy, normal status is not achieved (Cohen and Duncan, 1967). The reason for this is not fully understood. Nutritional problems after vagotomy. are not uncommon (Cox, Bond, Podmore, and Rose, 1964) and impaired ascorbic acid nutrition could be the result of diminished absorption of the vitamin due to the therapeutic hypochlorhydria.

The present study was constructed to confirm the effect of vagotomy on ascorbic acid nutrition in a larger group of patients, and to determine whether a relation exists between gastric acid output and the leucocyte ascorbic acid level after vagotomy.

\section{Methods}

Of the 40 patients originally studied, seven defaulted from follow-up and have been excluded. The remainder $(27$ men and 6 women) were aged 18 to 68 years, mean 45 years (S.D. $\pm 11 \cdot 3$ ). All had long-standing symptoms and had been selected for surgery before inclusion in this survey.

The dietary ascorbic acid levels were estimated before and after surgery by means of a questionnaire based on the tables of McCance and Widdowson (1960). Results were expressed as $\mathrm{mg} /$ day. Leucocyte ascorbic acid levels were estimated by the method of Denson and Bowers (1961). Fractionation of the cells and plasma was carried out within a few minutes of collection to minimize the uptake of ascorbic acid by the cells from the plasma. Though this method in fact measures the ascorbic acid content of the buffy layer, which contains both leucocytes and platelets, the results are conventionally expressed as $\mu \mathrm{g} / 10^{8}$ W.B.C. When the white count or platelet count is abnormal a correction factor is necessary (Gibson, Moore, and 
Goldberg, 1966); in this series, however, white count and platelet count carried out at the time of sampling were all within normal limits.

Truncal vagotomy was performed in all cases. The drainage procedure was randomly selected (pyloroplasty in 13; gastroenterostomy in 18). Antrectomy was performed in addition to vagotomy in two patients who were found to have a coexisting gastric ulcer. An insulin test was carried out postoperatively, and all but three showed a negative response to 20 units of soluble insulin, according to the criteria of Hollander (1946). In those three the positive response occurred in the second hour, and as the significance of this finding remains in doubt they have not been excluded on the grounds of incomplete vagotomy.

Maximum acid output in response to $6 \mu \mathrm{g}$ of pentagastrin per kg (Multicentre Study, 1967) was determined before and after operation and expressed as peak acid output, defined as the sum of the two highest consecutive 15-minute outputs. The pentagastrin and insulin tests were performed in the early postoperative period and were not repeated at the later follow-up, which was from 6 to 15 months after operation, with a mean interval of 12 months (S.D. $\pm 2 \cdot 1$ ).

The results have been compared with the accepted minimum intake of ascorbic acid of $30 \mathrm{mg} /$ day, as recommended by the Medical Research Council (Bartley et al., 1953), and with the normal range of leucocyte ascorbic acid levels found by Denson and Bowers (1961) of 20-50 $\mu \mathrm{g} / 10^{8}$ W.B.C.

\section{Results}

There was no statistical difference between groups segregated by sex or by operative procedure. Accordingly all 33 patients have been considered as one group.

The mean preoperative dietary ascorbic acid level was $25.9 \mathrm{mg} /$ day (S.D. $\pm 17 \cdot 8$ ). The mean postoperative level was $52.6 \mathrm{mg} /$ day (S.D. \pm 30.3 ). The mean rise of $27.5 \mathrm{mg} /$ day (S.E. \pm 5.1$)$ is highly significant $(P<0.001)$. The mean preoperative leucocyte ascorbic acid level was $18.3 \mu \mathrm{g} / 10^{8}$ W.B.C. (S.D. $\pm 9 \cdot 7$ ). The mean postoperative level was $19 \cdot 7 \mu \mathrm{g} / 10^{8}$ W.B.C. (S.D. $\pm 6 \cdot 4$ ). The mean rise of $1.4 \mu \mathrm{g} / 10^{8}$ W.B.C. (S.E. \pm 1.8$)$ is not significant $(P>0.5)$.

In 22 patients $(66 \%)$ the preoperative leucocyte ascorbic acid level fell below the accepted lower limit of normal of $20 \mu \mathrm{g} / 10^{8}$ W.B.C. In this group, after operation, there was a mean rise of $5.0 \mu \mathrm{g} / 10^{8}$ W.B.C. (S.E. $\pm 1 \cdot 4$ ). This increase is highly significant $(P<0.001)$, and in 11 of the 22 the leucocyte ascorbic acid level was converted to normal (Fig. 1).

In the 33 patients as a whole there was no correlation between the rise in dietary ascorbic acid and the rise in leucocyte ascorbic

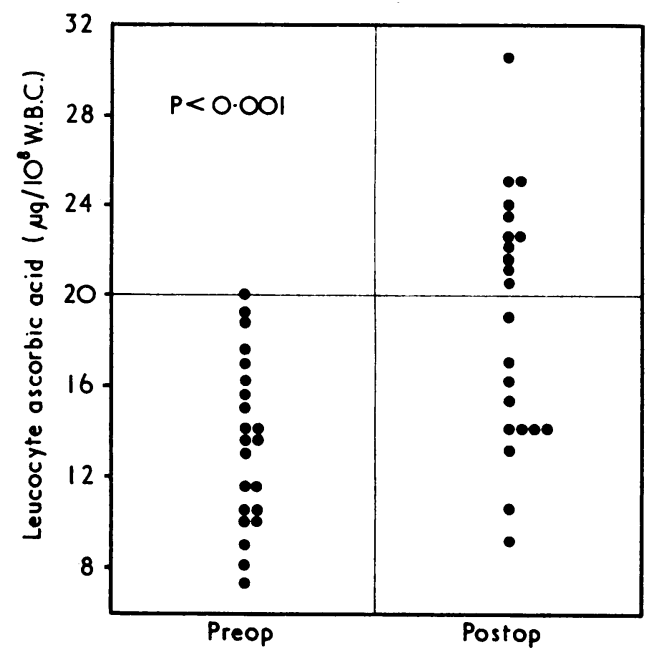

FIG. 1-Postoperative rise in leucocyte ascorbic acid levels in 22 patients with subnormal preoperative levels, with conversion of $50 \%$ to normal. acid. If we consider only those in whom the dietary and leucocyte ascorbic acid levels were subnormal before operation, however, such a correlation exists, and achieves probable significance $(P<0.05)$ (Fig. 2).

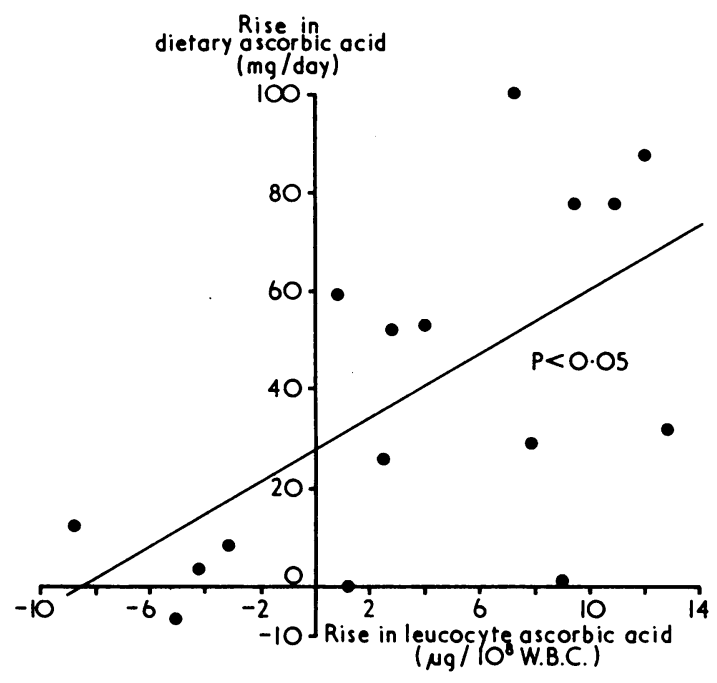

FIG. 2-Relation of rise in dietary ascorbic acid levels to rise in leucocyte ascorbic acid levels in 16 patients in whom both levels were subnormal preoperatively.

Of the 25 patients $(75 \%)$ whose dietary ascorbic acid intake was normal after operation, information regarding acid output was incomplete in four. In the remaining 21 patients there was a good negative correlation between the postoperative levels of leucocyte ascorbic acid and the amount by which peak acid output had been reduced $(P<0.02)$ (Fig. 3$)$. In other words, the smaller the reduction in gastric acidity, the higher the postoperative leucocyte ascorbic acid level is likely to be.

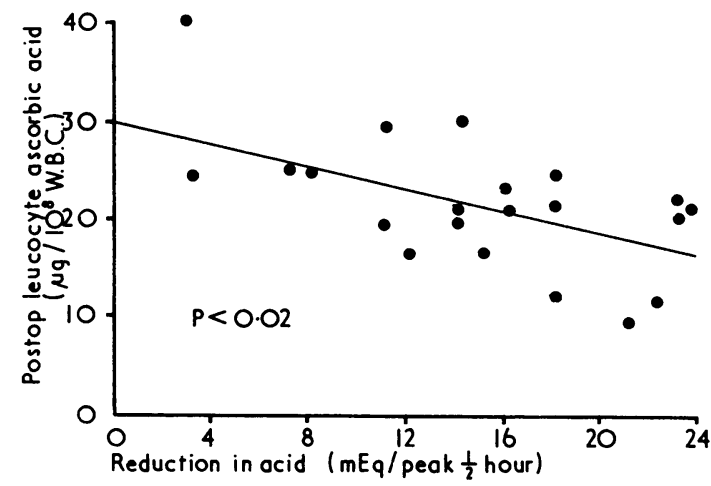

FIG. 3-Relation of postoperative leucocyte ascorbic acid levels to reduction in acid output in 21 patients with normal postoperative dietary intake.

\section{Discussion}

These results confirm that most patients suffering from peptic ulcer subsist on a diet deficient in ascorbic acid. In seven of this group the intake in fact was less than $10 \mathrm{mg} /$ day. Though this is theoretically in the "scorbutogenic" range (Bartley et al., 1953), none showed clinical evidence of frank scurvy. As might be expected this poor dietary intake was reflected in subnormal leucocyte ascorbic acid levels, though in this series there was no direct correlation between these two indices.

After vagotomy and drainage there was a highly significant rise in dietary intake of ascorbic acid which, in fact, is related to a general improvement in diet. The corresponding rise in leucocyte ascorbic acid levels was smaller, but nevertheless highly significant when only those with a subnormal preoperative level were considered. Before operation only $33 \%$ of patients had a 
leucocyte ascorbic acid level within the normal range; after operation $66 \%$ achieved normal status. This improvement in ascorbic acid nutrition, however, did not correlate well with the improvement in dietary intake, and only when one considered those in whom both dietary and leucocyte ascorbic acid levels were subnormal before operation did this correlation achieve significance (Fig. 2). This paradox may be explained on the grounds that, whereas the leucocyte ascorbic acid estimations were accurate, the dietary ascorbic acid levels were of necessity only approximations, which lessened the likelihood of good statistical correlation.

An alternative explanation, however, is that another factor is involved-an alteration in the absorption or utilization of ascorbic acid after vagotomy. It is striking that, in spite of the return to a full normal diet, the improvement in nutritional status is small, and that even those whose leucocyte ascorbic acid levels were converted to normal remain at the lower limit of normality. The absorption of ascorbic acid is known to be impaired by achlorhydria (Alt, Chinn, and Farmer, 1939), and it has been suggested that the therapeutic hypochlorhydria induced by vagotomy might result in malabsorption of ascorbic acid (Cohen and Duncan, 1967). In this study the reduction in peak half-hour output of acid was taken as an index of reduced gastric acidity, and there was a good negative correlation between this and the postoperative levels of leucocyte ascorbic acid. This finding lends weight to the argument that the hypochlorhydria induced by vagotomy was responsible for the failure of the ascorbic acid nutritional status to improve as much as might have been expected.

Animal experiments have shown that ascorbic acid is essential for the formation of mature collagen in healing wounds (Robertson and Schwartz, 1953), and there is a high incidence of poor ascorbic acid nutrition in patients suffering from wound dehiscence (Crandon et al., 1958). It is evident, then, that poor ascorbic acid nutrition represents a hazard to patients undergoing surgery.

From our findings one might postulate that the accepted minimum intake of $30 \mathrm{mg} /$ day for normal subjects is insufficient for patients suffering from peptic ulcer, even after surgical treatment. It would seem to be a wise precaution routinely to administer ascorbic acid supplements not only to peptic ulcer patients before operation but to any patient undergoing surgery on whom a vagotomy has previously been performed.

We are grateful to Professor A. W. Kay for permission to study patients under his care, and for advice in the preparation of this paper.

\section{References}

Alt, H. L., Chinn, H., and Farmer, C. J. (1939). American fournal of Medical Science, 197, 229.

Archer, H. E., and Graham, G. (1936). Lancet, 2, 364.

Bartley, W., Krebs, H. A., and O'Brien, J. R. P. (1953). Medical Research Council. Special Report Series No. 280.

Cohen, M. M. (1967). British Medical fournal, 2, 243.

Cohen, M. M., and Duncan, A. M. (1967). British Medical fournal, 4, 516.

Cox A. G., Bond, M. R., Podmore, D. A., and Rose, D. P. (1964). British Medical fournal 1, 465 .

Crandon, J. H., et al. (1958). New England fournal of Medicine 258, 105. Denson, K. W. and Bowers, E. F. (1961). Clinical Science, 21, 157.

Gibson, S. I. M., Moore, F. M. L., and Goldberg, A. (1966). British Medical Fournal, 1,1152 .

Harris, L. J., Abbasy, M. A., Yudkin, J., and Kelly, S. (1936). Lancet, 1, 1488.

Hollander, F. (1946). Gastroenterology, 7, 607.

Lazarus, S. (1937). British Medical fournal, 2, 1011.

McCance, R. A., and Widdowson, E. M. (1960) Medical Research Council. Special Report Series, No. 297.

Multicentre Study (1967). Lancet, 1, 291.

Platt, R. (1936). Lancet, 2, 366.

Portnoy, B., and Wilkinson, J. F. (1938). British Medical Fournal, 1, 554.

Robertson, W. van B., and Schwartz, B. (1953). Fournal of Biological Chemistry, 201, 689.

\title{
Vaginal Delivery under Caudal Analgesia after Caesarean Section and other Major Uterine Surgery
}

\author{
FERGUS P. MEEHAN, ARVIND S. MOOLGAOKER, JOHN STALLWORTHY
}

British Medical fournal, 1972, 2, 740-742

\section{Summary}

In the absence of a recurring indication for caesarean section vaginal delivery in subsequent pregnancy is a "trial of scar," with potentially serious implications for mother and baby. Labour under caudal analgesia was carefully supervised for 75 women with a surgically scarred uterus-due to lower segment section in 72 , abdominal hysterotomy in one, and transcavity myomectomy in two. Every caesarean scar was assessed digitally during labour and every uterus was examined after delivery. Caudal analgesia provided a painless labour and delivery and made scar assessment easy. Controlled intravenous Syntocinon infusion was given to

\footnotetext{
Nuffield Department of Obstetrics and Gynaecology, University of Oxford, Oxford

FERGUS P. MEEHAN, M.A.o., M.R.C.o.G., Lecturer (Present appointment : Consultant Obstetrician and Gynaecologist, Regional Hospital and University of Galway, Ireland)

ARVIND S. MOOLGÁOKER, M.D., Lecturer (Present appointment : Consultant Gynaecologist and Obstetrician, Basingstoke District Hospital, Basingstoke, Hants.

JOHN STALLWORTHY, F.R.c.s., F.R.C.o.G., Professor
}

25 patients. One scar dehiscence occurred early in labour and one in the second stage. Seventy mothers had 71 vaginal deliveries with one pair of twins and one breech. There was one stillbirth and no neonatal death. There were five repeat sections.

\section{Introduction}

Craigin's (1916) old dictum, "once a caesarean, always a caesarean," has been abandoned and should be replaced by "once a caesarean, always a hospital delivery." His statement referred to classical section, but has since been interpreted by many to include the lower segment operation. When no recurring indication exists and the vertex presents, vaginal delivery should be anticipated. That this is not universally accepted is evident from the fact that in New York City in 1964 47\% of sections were repeat operations (Douglas, 1967). A common and more conservative approach is for patients in a subsequent pregnancy to have a trial of labour. We prefer the term "trial of scar" while admitting that a trial of uterine performance is also involved. We believe that carefully supervised caudal analgesia increases the prospect of success for the reasons which follow.

It makes it possible to assess the lower segment scar from the time the cervix is effaced and two fingerbreadths dilated (see 